\title{
Complications of permanent cardiac pacing in patients with persistent left superior vena cava
}

\author{
Anna Polewczyk ${ }^{1}$, Andrzej Kutarski ${ }^{2}$, Elżbieta Czekajska-Chehab ${ }^{3}$, Piotr Adamczyk ${ }^{3}$, \\ Krzysztof Boczar², Maciej Polewczyk ${ }^{4}$, Marianna Janion ${ }^{1,5}$ \\ ${ }^{1} 2^{\text {nd }}$ Clinical Cardiology Department, District Hospital, Kielce, Poland \\ ${ }^{2}$ Department of Cardiology, Medical University, Lublin, Poland \\ ${ }^{3}$ First Faculty of Medicine, Medical University of Warsaw, Warsaw, Poland \\ ${ }^{4}$ Department of Radiology, Medical University, Lublin, Poland \\ ${ }^{5}$ Department Sciences of Healthy, The Jan Kochanowski University, Kielce, Poland
}

\begin{abstract}
Background: Persistent left superior vena cava (PLSVC) is present in about $0.3-0.5 \%$ of the general population and in about $12 \%$ of patients with other abnormalities. This congenital anomaly is usually asymptomatic and does not cause any physiological problems. However, it may become a significant problem in multiple clinical situations. Various complications related to PLVSC are encountered in anesthesiological, nephrological, oncological and cardiological procedures. The presence of PLSVC is usually incidentally detected during placement of pacemaker (PM), implantable cardioverter-defibrillator (ICD) and cardiac resynchronization therapy (CRT) leads. Technical difficulties during lead positioning (especially ventricular leads) are commonly known and often described in the literature. The purpose of the present study was to evaluate the specific methods used for implantation of increasingly complicated pacing systems, finding an optimal strategy in patients with PLSVC, especially with electrotherapy complications.
\end{abstract}

Methods: We performed a single-center retrospective analysis of 11 patients ( 7 women and 4 men, mean age $60.4 \pm 13$ years) with PLSVC hospitalized in single Cardiology Department between 2000 and 2012. The clinical characteristic, indications for PM/ICD/CRT implantation, technique of implantation and complications were evaluated.

Results: In PLSVC patients, different indications for pacing or resynchronization therapy were represented: sick sinus syndrome (SSS) in 4 patients, $3^{\text {rd }}$ degree atrio-ventricular $(A V)$ block in 4 patients, dilated cardiomyopathy with left bundle branch block in 2 patients, dilated cardiomyopathy and non-sustained ventricular tachycardia episodes in 1 patient. In patients no. 1, 3, 4 and 10 the complications necessitated the change of leads or type of pacing. Transvenous lead extraction was successfully performed in patient no. 1 and 10 with re-implantation of new leads via PLSVC in patient no. 1 and via right superior vena cava in patient no. 10. Patient no. 3 received an additional ventricular lead via PLSVC because of $2^{\text {nd }}$ degree AV block (formerly atrial lead implanted due to SSS). In patient no. 4 with left atrial pacing (lead in coronary sinus), prosthetic mitral valve replacement was combined with epicardial ventricular lead placement. Patients no. 2 and 7 received a CRT device, without technical problems in patient no. 7, whereas in patient no. 2 due to difficulties with left

Address for correspondence: Anna Polewczyk, MD, PhD, II Clinical Cardiology Department, District Hospital, ul. Grunwaldzka 45, 25-736 Kielce, Poland, tel: +48 4136715 08, fax:+48 4136714 56, e-mail: annapolewczyk@wp.pl Received: 22.02.2013 Accepted: 14.01.2014 
ventricular lead positioning a hybrid approach to epicardial lead pacing was used. In patient no. 8 an ICD was implanted with difficulty in placing defibrillator lead. Patient no. 5 received 2 atrial leads via PLSVC with successful biatrial pacing; patient no. 6 with the necessity of DDD pacing had a (ventricular) lead for left atrial pacing and a typical right ventricular lead. In patients no. 9 and 11 typical DDD pacing was used with contralateral placement of the leads due to anatomical and technical differences. After 12 years of follow-up the survival is 90.9\%. Late electrotherapy complications have developed only in patient no. 8 (problems with the defibrillator lead).

Conclusions: Patients with PLSVC are a very heterogeneous group with different indications for pacing, therefore individualization of therapy is required. Technical complications connected with pacing of the right heart chambers are commonly known, hence transvenous left atrial or left ventricular lead implantation should be attempted. In case of difficulties in transvenous positioning of the lead, a hybrid or isolated cardiac surgery technique should be considered. Because of the increasing number of electrotherapy complications, these problems are also present in PLSVC patients. Transvenous lead extraction with re-implantation of a pacing system has not been reported yet. For this reason a thorough evaluation of the venous system is required in PLSVC patients before intervention. (Cardiol J 2014; 21, 2: 128-137)

Key words: persistent left superior vena cava, electrotherapy complications, transvenous leads extraction

\section{Introduction}

Persistent left superior vena cava (PLSVC) is a congenital anomaly found in about $0.3-0.5 \%$ of the general population and in about $12 \%$ of patients with other abnormalities [1]. The PLSVC as an isolated venous anomaly is usually asymptomatic, however, it may become a significant problem when using some treatment strategies. Various complications related to PLVSC are encountered in anesthesiological, nephrological, oncological and cardiological procedures [1-5]. In cardiology, the presence of PLSVC is usually incidentally detected during placement of pacemakers (PM), implantable cardioverter-defibrillators (ICD) and cardiac resynchronization therapy (CRT) devices. Technical difficulties during lead positioning (especially ventricular leads) are commonly known and often reported in the literature.

The purpose of the present study was to describe the methods and evaluate the efficacy of permanent PM implantation, and to analyze the incidence and treatment of complications in this group of patients.

\section{Methods}

We performed a single-center retrospective analysis of 11 patients ( 7 women and 4 men, mean age $60.4 \pm 13$ years) with PLSVC hospitalized between 2000 and 2012 for PM implantation or replacement. Patients were included if they had PLSVC confirmed before procedure. In the past, preoperative venous angiography was frequently utilized before lead insertion and in all presented patients diagnosis was establish during lead implantation. An atypical guide-wire route (or distal part of lead inserted via cephalic vein) course along left spine shadow suggested PLSVC presence. In this situation venous angiography served to exclude arterial route. All of the persons included represented indications to different interventions: 2 patients required transvenous lead extraction (TLE) due to electrotherapy complications, the next 6 were qualified to implantation or upgrading systems, in another 3 patients with diagnosis of dilated cardiomyopathy the necessity of implantation ICD or CRT systems was confirmed. In all these patients anatomy of the veins of the thorax, technical problems with lead implantation in the right heart chambers, technical solutions obviating anatomically difficult areas and the presence of pacing complications and failure were evaluated. The details were demonstrated in Table 1.

The study was approved by the local bioethical committee and all patients gave their informed consent. 
Table 1. Baseline characteristics of the patients.

\begin{tabular}{|c|c|c|c|c|c|c|}
\hline Patients & $\begin{array}{c}\text { Age } \\
\text { [years] }\end{array}$ & Gender & $\begin{array}{l}\text { Indications for } \\
\text { PM/ICD/CRT } \\
\text { implantation }\end{array}$ & $\begin{array}{l}\text { Anatomical } \\
\text { variant }\end{array}$ & $\begin{array}{l}\text { Type of } \\
\text { pacing }\end{array}$ & Interesting \\
\hline 1 & 82 & M & $\begin{array}{l}\text { Chronic AF } \\
\text { with AVB } \\
\text { III degree }\end{array}$ & $\begin{array}{l}\text { Double (paired) } \\
\text { VCS; favorable } \\
\text { angle CS/TV }\end{array}$ & $\begin{array}{l}\text { VVI on the right } \\
\text { side; TLE with } \\
\text { re-implantation } \\
\text { to the left side due } \\
\text { to pocket infection }\end{array}$ & $\begin{array}{l}\text { Easy new RV lead } \\
\text { placement }\end{array}$ \\
\hline 2 & 65 & $F$ & $\begin{array}{l}\text { Dilated } \\
\text { cardiomyopathy, } \\
\text { LVEF } 30 \% \text {, LBBB }\end{array}$ & $\begin{array}{l}\text { Double (paired) } \\
\text { VCS; favorable } \\
\text { angle CS/TV; inac- } \\
\text { cessible CS branch }\end{array}$ & CRT-D & $\begin{array}{l}\text { Necessity of } \\
\text { epicardial LV lead } \\
\text { placement during } \\
\text { another procedure }\end{array}$ \\
\hline 3 & 76 & $F$ & $\begin{array}{l}\text { SSS, AVB } \\
\text { II degree }\end{array}$ & $\begin{array}{l}\text { Probably double } \\
\text { (paired) VCS; favo- } \\
\text { rable angle CS/TV; } \\
\text { visible CS branch }\end{array}$ & $\begin{array}{l}\text { AAl - upgrading } \\
\text { to DDD }\end{array}$ & $\begin{array}{l}\text { There was a not } \\
\text { applied chance for } \\
\text { more favorable } \\
\text { LV pacing }\end{array}$ \\
\hline 4 & 55 & $\mathrm{~F}$ & $\begin{array}{l}\text { Artificial mitral } \\
\text { valve, brady- } \\
\text {-tachycardia } \\
\text { syndrome with } \\
\text { SSS, developing } \\
\text { chronic AF }\end{array}$ & $\begin{array}{l}\text { Probably single } \\
\text { (very large CS) } \\
\text { venography done } \\
\text { but not recorded }\end{array}$ & $\begin{array}{c}\mathrm{AAI} \text { - upgrading } \\
\text { to } \mathrm{VVI}\end{array}$ & $\begin{array}{l}\text { Selection pacing } \\
\text { of LA as the first } \\
\text { choice and } \\
\text { abandonment } \\
\text { idea for RA pacing }\end{array}$ \\
\hline 5 & 60 & $\mathrm{~F}$ & $\begin{array}{c}\text { SSS with } \\
\text { brady-tachycardia } \\
\text { syndrome and } \\
\text { inter-atrial block }\end{array}$ & $\begin{array}{l}\text { Single (description } \\
\text { of venography) }\end{array}$ & Bi-atrial pacing & $\begin{array}{l}\text { Straight lead pace } \\
\text { lateral wall of RA } \\
\text { but J-shaped lead } \\
\text { - excellently we- } \\
\text { dged in enlarged CS }\end{array}$ \\
\hline 6 & 52 & $\mathrm{~F}$ & $\begin{array}{l}\text { SSS, potential AV } \\
\text { conduction } \\
\text { disorders } \\
\text { (Wenckebach } \\
\text { point } 120 / \text { min); } \\
\text { paroxysmal AF }\end{array}$ & $\begin{array}{l}\text { Probably double } \\
\text { but implantation } \\
\text { right side system } \\
\text { in another }\end{array}$ & DDD & $\begin{array}{l}\text { Selection pacing } \\
\text { of LA as the first } \\
\text { choice and easy } \\
\text { new RV lead }\end{array}$ \\
\hline 7 & 54 & M & $\begin{array}{l}\text { Dilated } \\
\text { cardiomyopathy, } \\
\text { LVEF } 30 \% \text {, LBBB }\end{array}$ & $\begin{array}{l}\text { Probably single } \\
\text { (more central } \\
\text { course of VCS) } \\
\text { venography was } \\
\text { not done }\end{array}$ & CRT-P & $\begin{array}{l}\text { Very easy LV lead } \\
\text { implantation and } \\
\text { its stable position }\end{array}$ \\
\hline 8 & 35 & M & $\begin{array}{c}\text { Dilated } \\
\text { cardiomyopathy, } \\
\text { LVEF } 20 \% \text {, } \\
\text { non-sustained VT }\end{array}$ & $\begin{array}{l}\text { Single PLSVC, } \\
\text { extreme } \\
\text { non-favorable } \\
\text { angle CS/TV }\end{array}$ & ICD & $\begin{array}{l}\text { Impossibility to } \\
\text { pass from CS to RV, } \\
\text { ICD lead location in } \\
\text { mid cardiac vein }\end{array}$ \\
\hline 9 & 56 & $\mathrm{~F}$ & AVB II degree & $\begin{array}{c}\text { Single PLSVC, } \\
\text { non-favorable angle } \\
\text { CS/TV, difficult } \\
\text { anatomy }\end{array}$ & DDD & $\begin{array}{l}\text { It was necessary } \\
\text { to create of the } \\
\text { ventricular lead } \\
\text { loop, in RA to pass } \\
\text { tricuspid valve }\end{array}$ \\
\hline 10 & 52 & M & AVB III degree & $\begin{array}{c}\text { Double (paired) } \\
\text { VCS }\end{array}$ & $\begin{array}{l}\text { DDD - TLE due } \\
\text { to dysfunction of } \\
\text { the leads with re- } \\
\text {-implantation on } \\
\text { the right side }\end{array}$ & $\begin{array}{l}\text { Selection of the } \\
\text { simplest solution } \\
\text { — right side } \\
\text { system } \\
\text { implantation }\end{array}$ \\
\hline 11 & 78 & $\mathrm{~F}$ & $\begin{array}{c}\text { SSS with } \\
\text { brady-tachycardia } \\
\text { syndrome and } \\
\text { AVB I degree }\end{array}$ & $\begin{array}{l}\text { Single VCS; } \\
\text { favorable } \\
\text { angle CS/TV }\end{array}$ & DDD & $\begin{array}{l}\text { Only one case } \\
\text { where both leads } \\
\text { were located in } \\
\text { selected but not in } \\
\text { constrained places }\end{array}$ \\
\hline
\end{tabular}

$\mathrm{AF}$ - atrial fibrillation; AVB — atrio-ventricular block; CS — coronary sinus; CRT — cardiac resynchronization therapy; $\mathrm{F}$ - female; ICD — implantable cardioverter-defibrillator; LA — left atrium; LBBB — left bundle branch block; LVEF — left ventricular ejection fraction; LV — left ventricle; M — male; PM — pacemaker; PLSVC — persistent left superior vena cava; RA — right atrium; RV — right ventricle; SSS — sick sinus syndrome; TLE — transvenous lead extraction; VCS — vena cava superior; TV — tricuspid valve; VT — ventricular tachycardia 


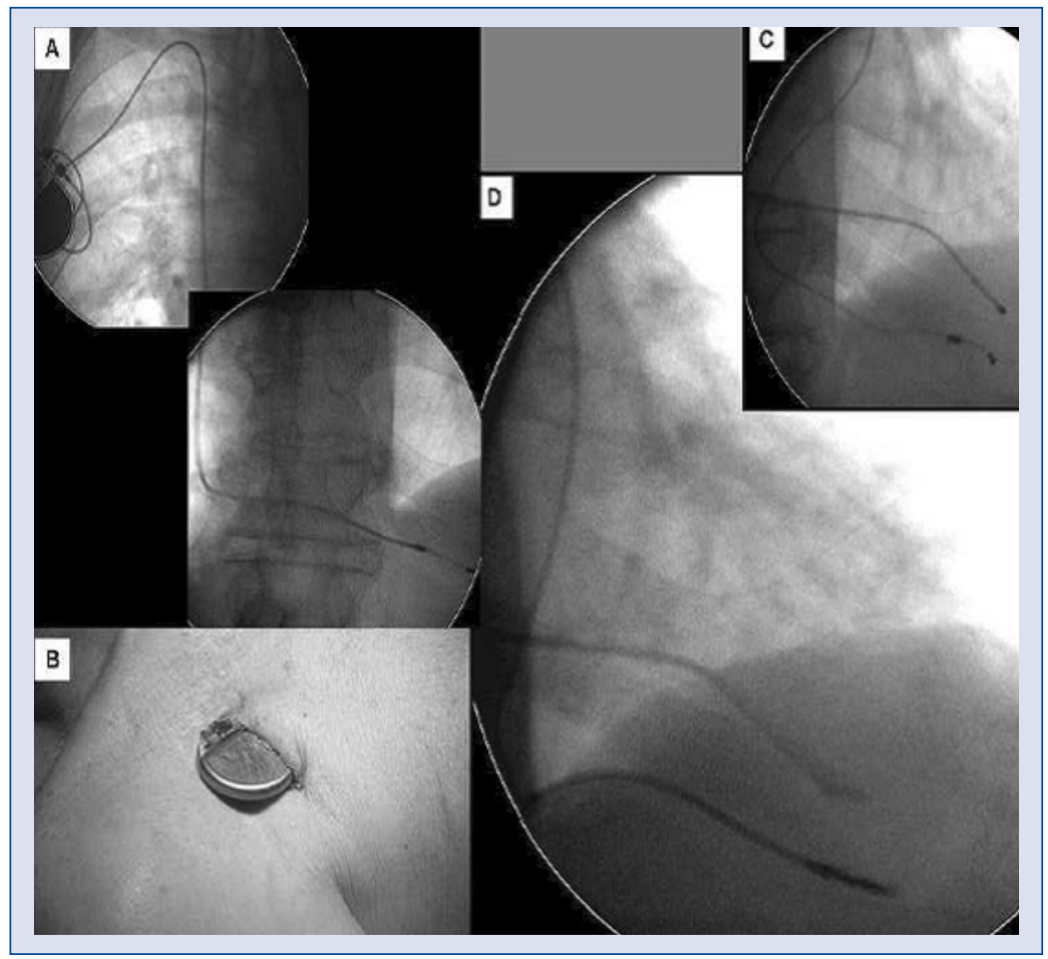

Figure 1. Infected VVI pacemaker implanted in the right side of the chest (A, B). The device was extracted using temporary pacing via femoral approach. Persistent left superior vena cava was found during implantation of a new system. First attempt to use the coronary sinus branch for left ventricular pacing failed but conventional right ventricular pacing proved easy (C, D).

\section{Results}

The study population consisted of 7 women and 4 men, mean age of $60.4 \pm 13$ years, with indications for PM implantation due to sick sinus syndrome (SSS) (4 patients), dilated cardiomyopathy with left bundle branch block (2 patients) or ventricular tachycardia episodes (1 patient), and atrio-ventricular (AV) blocks (4 patients). The patients received pacing devices in accordance with the indications found (Table 1).

After over 12 years of follow-up 4 patients developed complications that necessitated lead re-implantation (patients no. 1 and 10) or lead replacement/pacing mode switch (patients no. 3 and 4). Patient number 1 developed pocket infection on the right side of the chest at 5 years after VVI implantation and according to the I class of Heart Rhythm Society consensus - was selected for TLE [6]. During the procedure the patient required temporary cardiac pacing (temporary pacing lead was introduced via the femoral vein). The lead was liberated using a pair of green Byrd dilators $\left(\mathrm{Cook}^{\circledR}\right)$. TLE procedure was difficult because the lead was strongly grown into the right ventricle wall. Nevertheless, TLE run without complica- tions and any specific tools or actions weren't used. During implantation of a new PM on the left side of the chest an anatomical anomaly (PLSVC) was found. Left ventricular pacing failed (phrenic nerve stimulation through only one accessible great vein); however, it was possible to pass the lead through the right atrium to the right ventricle, and the right ventricular lead was successfully re-implanted (Fig. 1).

In patient number 3 with an atrial lead implanted via a PLSVC 6 years before due to SSS it was necessary to switch the pacing mode to DDD due to paroxysmal $2^{\text {nd }}$ degree AV block. Because of potential problems with vascular access, prior to the procedure venography was performed, which revealed normal flow in the PLSVC. Right ventricular lead was successfully inserted via the PLSVC emptying into the coronary sinus (CS) at a convenient angle relative to the tricuspid valve, although hemodynamically more favorable left ventricular pacing could be taken into account.

Patient number 4 developed brady-tachycardia syndrome at 3 years after mitral valve implantation. In 2001 left atrial lead was inserted via the PLSVC and positioned in the CS, which resulted in suppression of atrial arrhythmias. Eleven years 


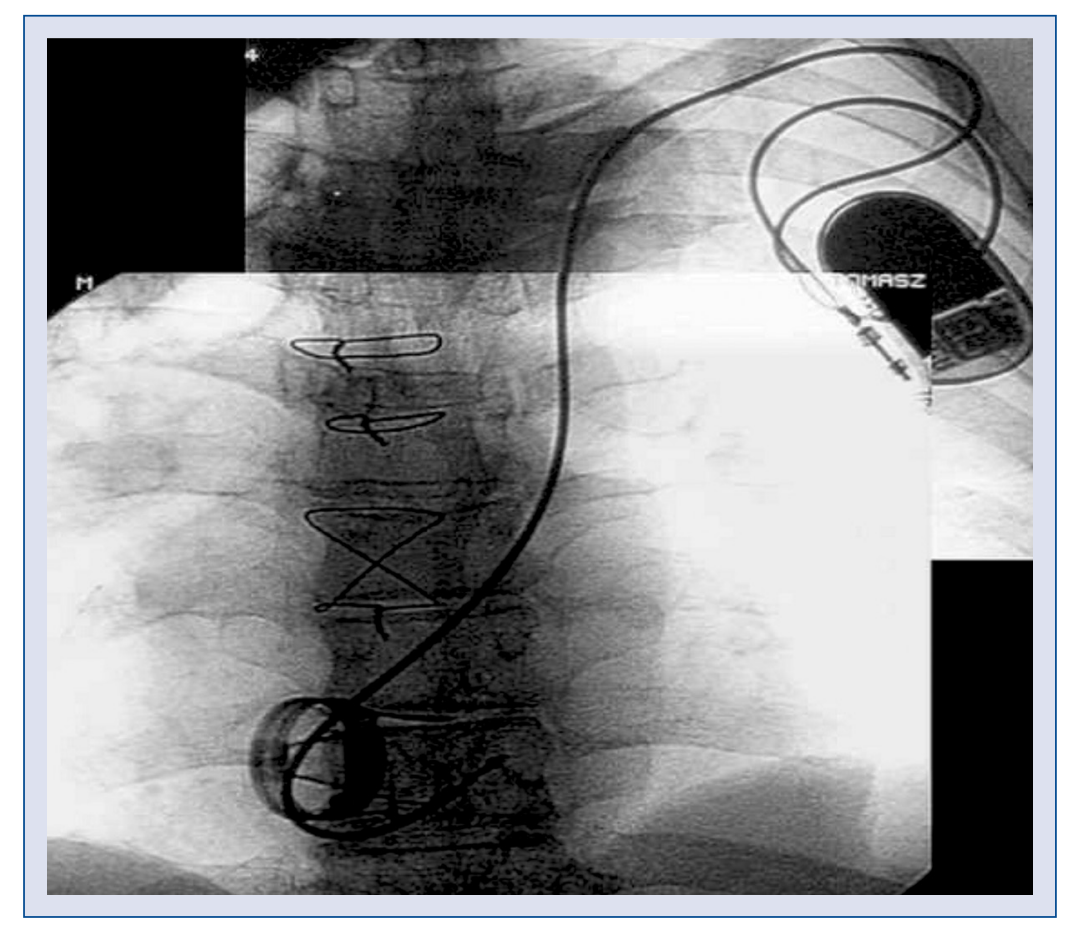

Figure 2. Mechanical mitral valve and severe brady-tachycardia syndrome. Permanent (enlarged) coronary sinus ostium pacing as the simplest method of atrial resynchronization. Much more "symmetrical" atrial activation than during lateral wall right atrium pacing.

later the patient developed acute prosthetic valve thrombosis and permanent atrial fibrillation. The patient was selected for cardiac surgery with re-implantation of prosthetic valve. During the operation right ventricular pacing was achieved by positioning an epicardial ventricular lead, whereas left atrial lead was extracted transvenously later on (Fig. 2).

In patient number 10 symptoms of lead dysfunction developed at 6 years after DDD implantation. Patient complained about weakness and presyncope. During PM control the increase of ventricle lead resistance with periodical ineffectual pacing were revealed and the man was qualified for TLE with re-implantation of the new system. TLE was performed using the inner elastic yellow sheath of the Byrd dilator $\left(\mathrm{Cook}^{\circledR}\right)$. The procedure took place without complications, although the leads were already strongly rooted in the heart walls. Afterwards, the leads were re-implanted via the right superior vena cava (RSVC) and positioned in the right atrium and the right ventricle (Fig. 3).

Patients number 2 and 7 , because of dilated cardiomyopathy with cardiac asynchrony, were selected for CRT. In patient number 2 due to technical difficulties (marked enlargement of the CS) it was not possible to insert a pacing lead into the left ventricle via the PLSVC. Instead, a right atrial lead was placed in the right atrium, whereas a defibrillation lead with the entire CRT-D device was placed in the right ventricle. Then, an epicardial left ventricular screw-in lead was implanted via left mini-thoracotomy (Fig. 4).

Patient number 7 received a CRT-P device in 2002 with successful implantation of 3 leads via the PLSVC with left ventricular lead insertion being the easiest stage of the procedure.

Patient number 8 developed recurrent hemodynamically destabilizing ventricular tachycardia that necessitated implantation of an ICD. Venography prior to the procedure revealed absent RSVC. Because of the very inconvenient angle of the enlarged coronary ostium relative to the tricuspid valve 2 attempted insertions of the defibrillator lead via the PLSVC were unsuccessful. A third attempt was made, this time to insert the lead into the ostium of the middle cardiac vein, achieving efficient control/pacing/defibrillation.

Patients number 5, 6, 9 and 11 required double lead PM. Patient number 5 due to inter-atrial conduction disorders received a ventricular straight lead in the right atrium and a J-shaped lead in the $\mathrm{CS}$, which resulted in effective low-threshold bi-atrial pacing (Fig. 5). In patient number 6 with indications for DDD implantation an atrial pacing lead was placed in the CS ostium to achieve the 


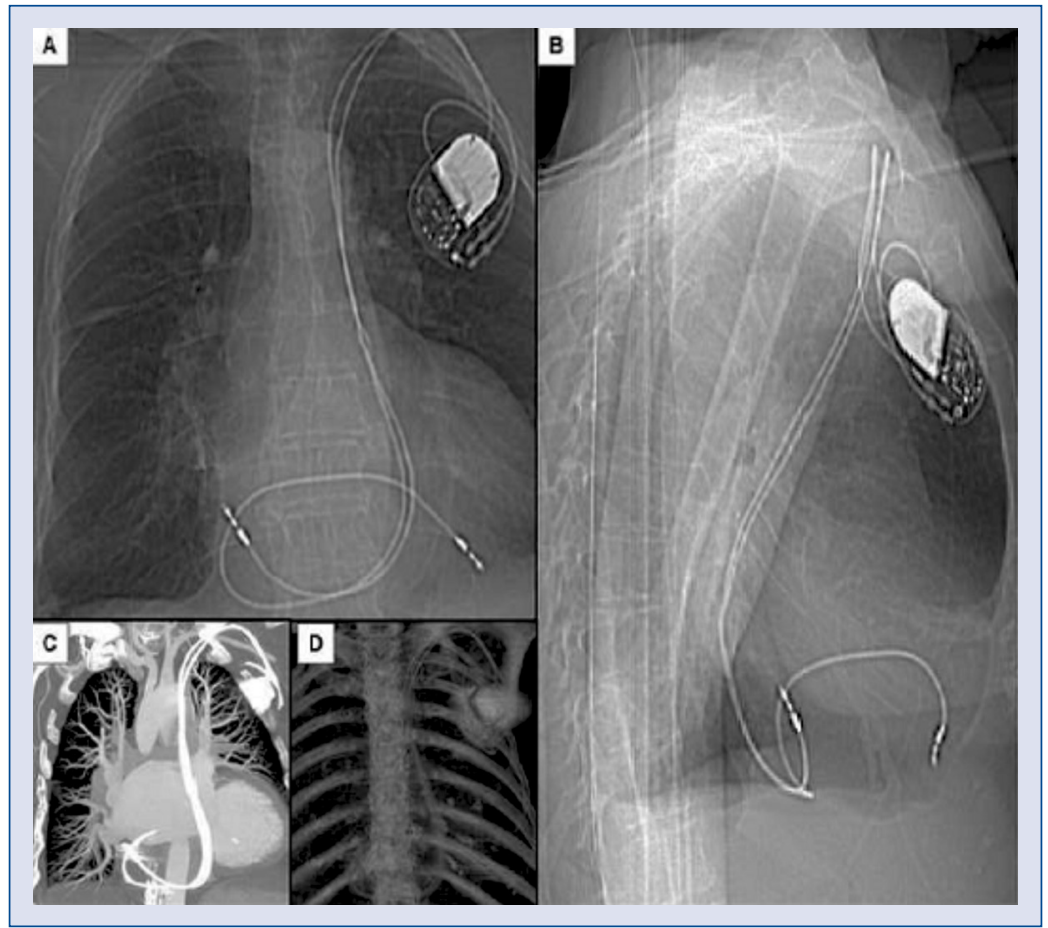

Figure 3. Successful DDD system implantation in spite of difficult anatomy. A ventricular lead loop in right atrium (RA) was created to pass the lead effectively through the tricuspid valve (A, B, C, D). The system has been working perfectly for nearly 3 years but both leads are located in a less favorable site (lateral and anterior RA wall). X-ray chest PA view seemed to indicate a possibility of passing the lead via persistent foramen ovale or atrial septal defect to the left ventricular lumen $(\mathbf{A})$ but another examination excluded this option.

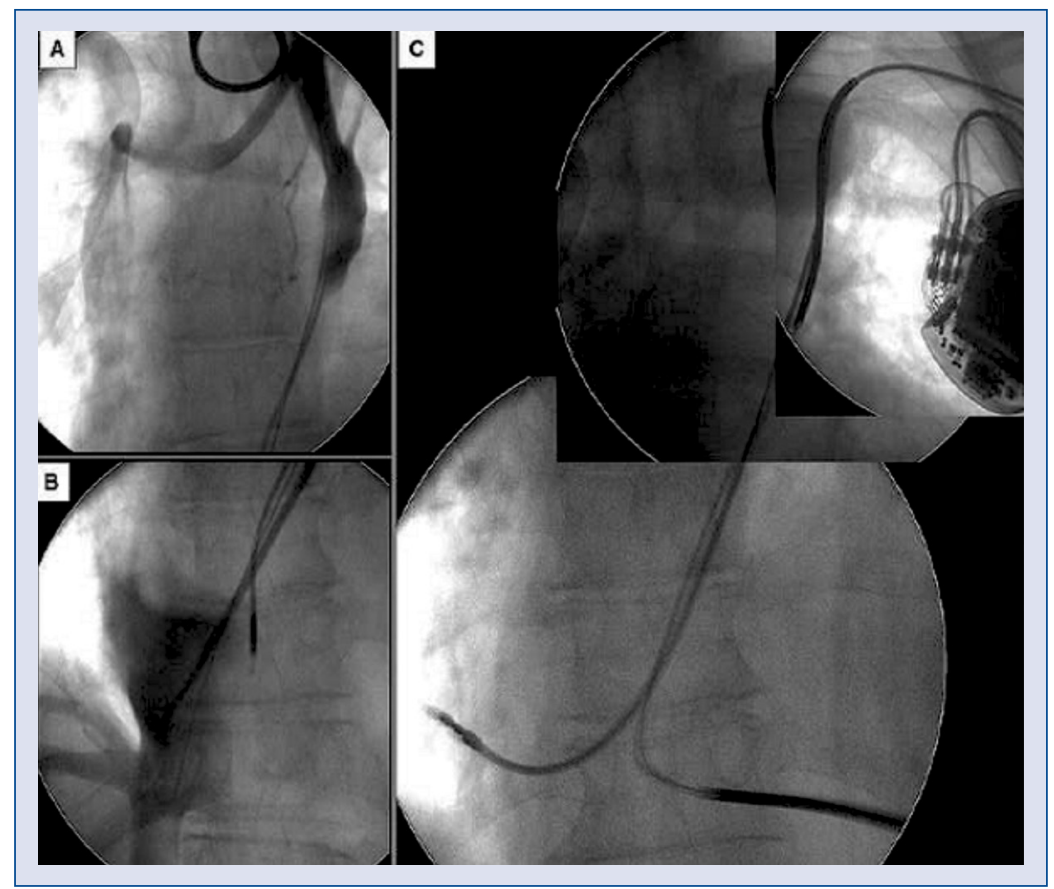

Figure 4. Implantation of a CRT-D device in a patient with double superior vena cava (A). Persistent left superior vena cava was connected with coronary sinus (CS) near the CS ostium (B); implantation of right atrium and right ventricle (implantable cardioverter-defibrillator) leads was easy but no CS branch was found. The patient received epicardial left ventricular lead implanted by left-sided mini thoracotomy several weeks later (C). 


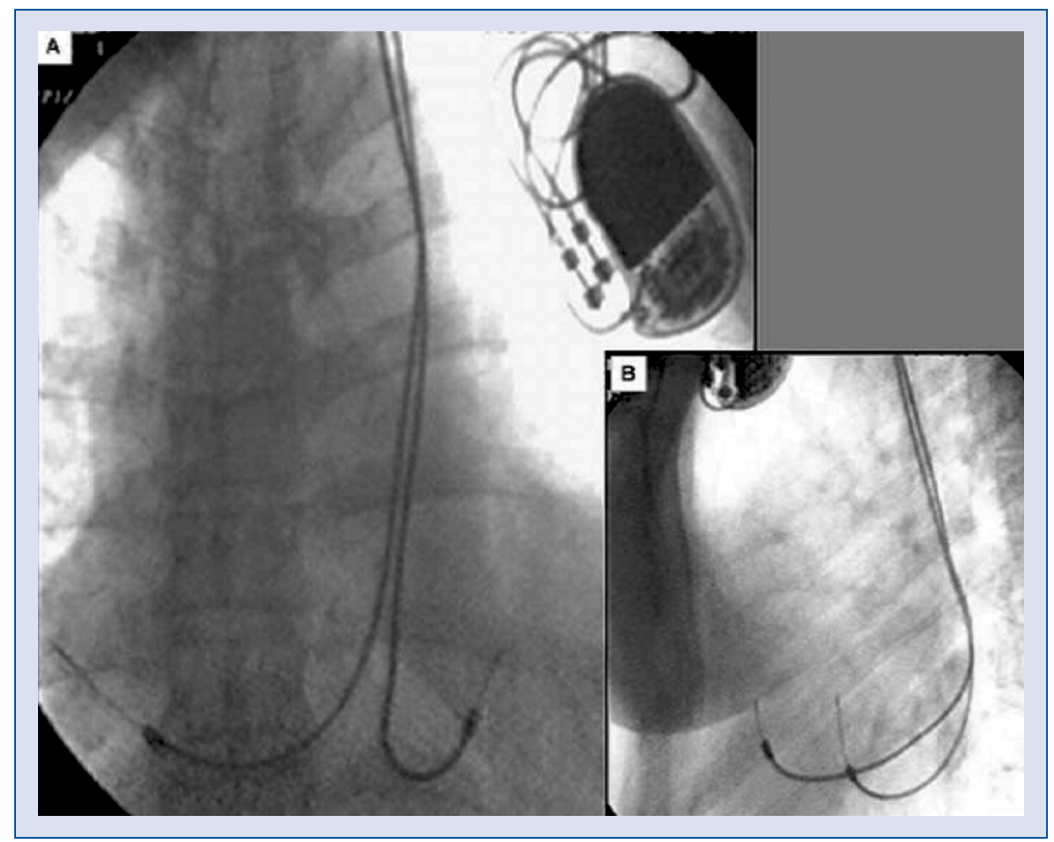

Figure 5. A, B. Still working bi-atrial pacing system for atrial resynchronization due to brady-tachycardia syndrome with severe inter-atrial block implanted 12 years before. Conventional straight lead for lateral wall right atrium pacing (unfavorable site from the electrophysiological viewpoint), but J-shaped lead was excellently wedged in enlarged coronary sinus enabling fine atrial resynchronization.

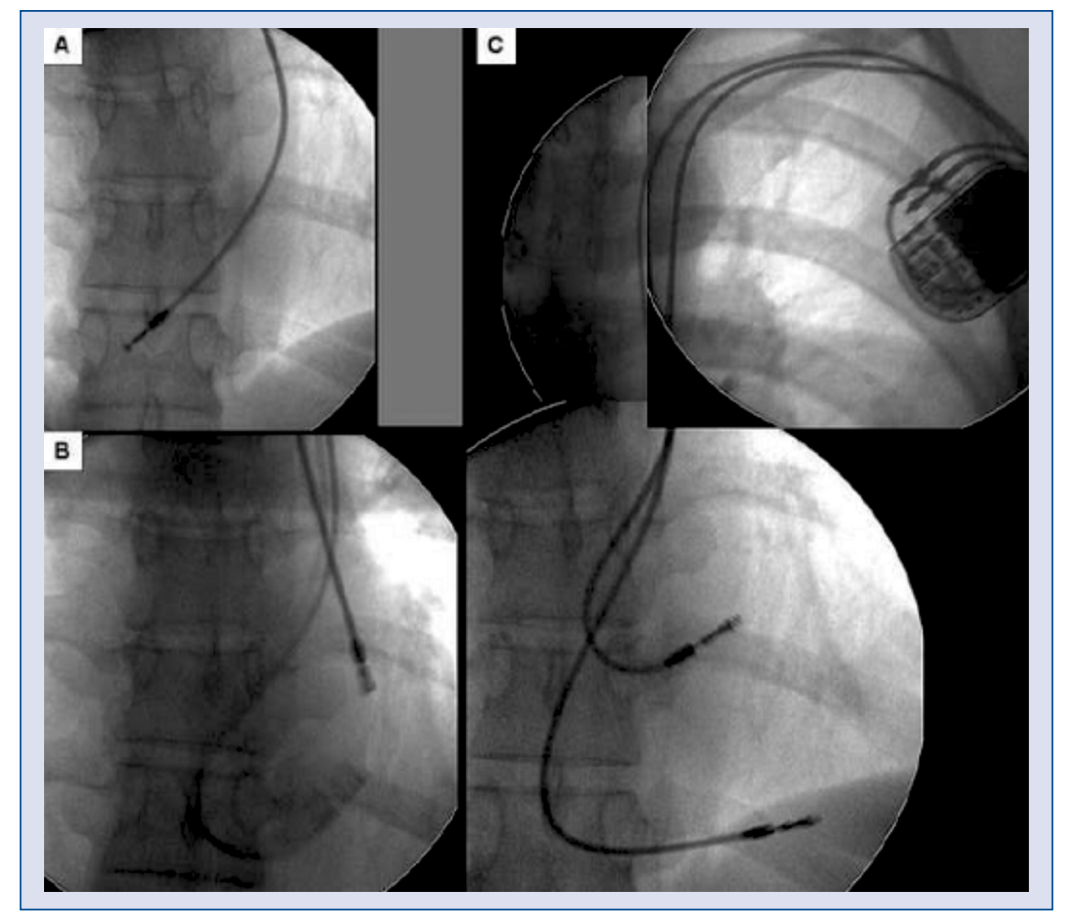

Figure 6. A, B, C. Implantation of a DDD pacing system. Atrial lead paces enlarged coronary sinus (CS) (left atrium). Implantation of right ventricle lead was relatively easy due to favorable angle of CS ostium relative to tricuspid valve. CS pacing as an interesting alternative for lateral wall right atrium pacing.

antiarrhythmic effect of left atrial pacing, whereas a right ventricular lead was positioned in the typical site (Fig. 6). Patients number 9 and 11 received typical DDD devices (right atrial and right ventri- 


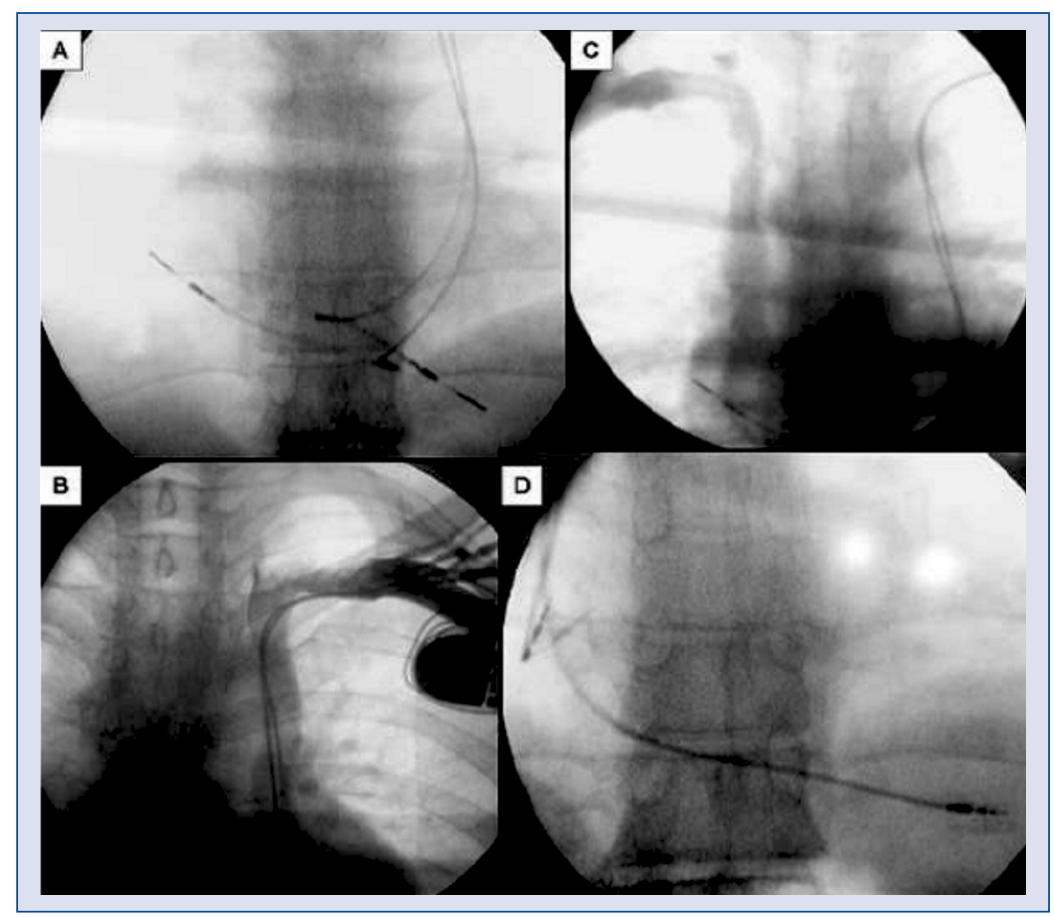

Figure 7. Patient with a DDD system serving for 6 years and dysfunction of both leads (A, B). Another favorable anatomical variant - double (paired) superior vena cava (C). Both leads were extracted and a new pacing system was implanted via the right superior vena cava, as easier for upgrading or lead extraction in the future (D).

cular leads), however due to extremely different anatomical conditions and technical difficulties, the final positions of the leads were entirely different (Fig. 7).

After 12 years of follow-up the survival is $90.9 \%$ (the actual fate of patient no. 7 with the CRT-P device remains unknown), with significant PM-related problems i.e. increases in defibrillation threshold detected in 1 patient - number 8 . However, no further intervention has been attempted and the patient is waiting for a heart transplant.

\section{Discussion}

PLSVC is a remnant of a vessel that is present in early embryological development. Initially, 2 symmetrical cardinal veins (right and left) form the main venous drainage system of the embryo. By the $8^{\text {th }}$ week of gestation the innominate vein connects the right and left anterior cardinal veins. The cephalic portion of superior cardinal veins form the internal jugular veins while the right anterior and common cardinal veins form the RSVC. The part of the left anterior cardinal vein caudal to the innominate vein normally regresses to become the ligament of Marshall. Failure of this regression is attributed to the formation of a PLSVC. The innominate vein may regress, but frequently it remains as another anatomical variant of the venous drainage [7]. PLSVC most frequently coexists with a normal RSVC, the distal part of the RSVC rarely regresses, which means that the PLSVC drains the caudal parts. Anatomical variants of PLSVC are significant from the clinical viewpoint - in $80-90 \%$ of cases the PLSVC drains into the right atrium (directly or through the CS), in the remaining $10-20 \%$ cases into the left atrium causing right-to-left shunt [8].

PLSVC has various practical implications and permanent $\mathrm{PM} / \mathrm{ICD} / \mathrm{CRT}$ placement can be challenging. The atypical venous flow is most often detected during implantation procedure. The operator's problem is to introduce the lead to the right side of the chest - it spontaneously moves down along the left side of the spine. It is very important to perform venous angiography - the visualization of PLSVC confluence with assessment of the angle of the most often orifice to the CS and possible double cava vein presence confirmation. Thereafter, according to the operator's experience, the leads could be implanted via PLSVC into right atrium and via right atrium and tricuspid valve - into right ventricle (often using specific tools). Less experienced operators more often implant the system at the opposite chest side after following right-side 
venous angiography, if anatomical conditions make it possible. The difficulties during implantation and helpful specific instruments are often described in the literature [9-12]. Experienced operators select more favorable electrophysiological and hemodynamic solutions: epicardial left heart pacing/ /sensing and very exceptionally - defibrillation. Currently, the first reports about this strategy have been published [13]. In the present study, a very experienced operator tried to perform the best options, individually adjusted to every patient. Additionally, currently presented PLSVC population is specific because of repeated procedures due to late electrotherapy complications or necessity to upgrade the system. In the present study there were important complications of permanent pacing (patient no. 1-PM pocket infection and patient no. 10 - lead dysfunction) that necessitated TLE with re-implantation due to limited venous access. Late electrotherapy and TLE complications in PLSVC patients have not been found in the available literature, however they may be expected to occur increasingly frequently. Most problems should be encountered in patients with extremely tortuous double-coil defibrillator leads placed in the right ventricle. The need to change pacing mode in patients with PLSVC (patients no. 3 and 4) poses another challenge. As in patients with pacing complications venous angiography should be performed to determine venous patency after lead insertion and to visualize alternative routes of pacing. Changes in pacing mode in single patients with PLSVC, as in patient number 3 , have been found successful after a thorough examination of venous drainage [14, 15]. Cardiac surgery may offer the opportunity to sew on an epicardial lead as in patient number 4. Epicardial lead placement is also recommended in patients with low left ventricular ejection fraction in whom CRT is indicated but insertion of a left ventricular lead via a PLSVC is challenging, in spite of the fact that perioperative risk is extremely high in these patients, and surgical technique may make it difficult to position the lead with suboptimal resynchronization $[16$, 17]. In the present study, patient number 2 underwent a hybrid procedure, namely transvenous implantation of a right atrial and right ventricular lead combined with epicardial placement of a left ventricular lead, achieving a spectacular clinical improvement due to effective resynchronization. The same approach was reported in a group of patients with PLSVC [18]. However, CRT implantation in patients with PLSVC is not always a challenge. Reports of successful CRT procedures using va- rious diagnostic techniques have been published for many years [16, 19-22]. In the present study, patient number 7 underwent a successful CRT implantation in 2002. It is important to know that in a large funnel-shaped sinus it is not possible to perform selective venography and create the pressure that propels a contrast dye with blood to the cardiac veins. Both visualization of vein orifice and insertion of the lead in one of the cardiac veins on the posterior or lateral myocardial wall is largely a matter of chance.

Another important issue in patients with PLSVC and high risk of sudden cardiac death is the appropriate insertion of a defibrillator lead to achieve low defibrillation threshold. Some evidence show that in such patients pulse generators should be implanted in the left side of the chest to create an optimal electric field [23]. Most investigators recommend single-coil leads to exclude potential displacement of the coils, which is more likely to occur in patients with PLSVC. However, with the availability of telemetry to change the configuration of defibrillators it is possible to use double-coil leads $[18,24]$. In the present study, placement of a defibrillator lead in patient number 8 was very difficult because of absent RSVC and anatomically unfavorable ostium of the enlarged CS. The only possible solution was insertion of the lead into the ostium of the middle cardiac vein to achieve effective defibrillation. The patient received a double-coil lead to improve defibrillation of the posterior wall of the enlarged myocardium.

The remaining 2 cases in the present study are apparently simple examples of pacing device implantation. Patient number 5 with SSS developed inter-atrial conduction disorders and a decision was made to use bi-atrial pacing, so far not applied in patients with PLSVC. Of interest is skillful use of a ventricular straight lead in the lateral wall of the right atrium and a J-shaped lead in the CS to achieve low threshold pacing (the procedure was performed during the time when screw-in leads were not available in Poland). A similarly interesting example of atrial lead placement can be seen in patient number 6 . A screw-in lead in the CS wall resulted in effective left atrial pacing with an antiarrhythmic effect. Long-term effective left atrial pacing in patient number 4 is also worth mentioning. All these examples show that problems resulting from difficult access to right-sided cardiac chambers and also - or first of all - potential proarrhythmic and hemodynamically unfavorable pacing of the lateral wall of the right atrium can be avoided. 


\section{In brief}

Patients with PLSVC are a very heterogeneous group with different anatomic conditions, therefore individualization of therapy is required. Technical problems with implantation of complex devices may make it difficult to use appropriate pacing mode, and in case of difficult access to the right heart, left atrial or left ventricular pacing via a lead inserted in the CS appears to be an interesting therapeutic option.

Epicardial pacing should be considered in case of difficulties in transvenous placement of the lead.

Because of an increasing number of electrotherapy complications, these problems are also present in PLSVC patients and may cause difficulties in TLE with re-implantation of a pacing system in case of limited venous access. For this reason a thorough evaluation of the venous system is required in PLSVC patients before re-intervention to reduce the risk of further complications.

\section{Conclusions}

1. PLSVC is present in about $0.3-0.5 \%$ of the patients selected for implantation of a PM/ /ICD/CRT device.

2. PLSVC frequently (5/11 cases) coexists with a normal RSVC.

3. PLSVC most frequently (in all 11 patients) is emptying into the enlarged CS, while the CS orifice relative to the tricuspid valve may be at an inconvenient angle, thus limiting the possibility of passing the lead through the tricuspid valve.

4. Right atrial pacing in patients with PLSVC is limited to the lateral wall of the atrium.

5. PLSVC provides an opportunity for transvenous left ventricular pacing.

6. Extraction of grown-in right ventricular leads inserted via PLSVC may pose a new challenge in the future.

\section{Conflict of interest: none declared}

\section{References}

1. Povoski SP, Khabiri H. Persistent left superior vena cava: Review of the literature, clinical implications, and relevance of alterations in thoracic central venous anatomy as pertaining to the general principles of central venous access device placement and venography in cancer patients. World J Surg Oncol, 2011; 28: 173.

2. Rigatelli G. Congenitally persistent left superior vena cava: A possible unpleasant problem during invasive procedures. J Cardiovasc Med (Hagerstown), 2007; 8: 483-487.

3. Schreiber KL, Matsusaki T, Bane BC et al. Accidental insertion of a percutaneous venovenous cannula into the persistent left superior vena cava of a patient undergoing liver transplantation. Can J Anaesth, 2011; 58: 646-649.

4. Parreira LF, Lucas CC, Gil CC et al. Catheterization of a persistent left superior vena cava. J Vasc Access, 2009; 10: 214-215.

5. Jang YS, Kim SH, Lee DH et al. Hemodialysis catheter placement via a persistent left superior vena cava. Clin Nephrol, 2009; 71: 448-450.

6. Wilkoff BL, Love CJ, Byrd CL et al. Transvenous lead extraction: Heart Rhythm Society expert consensus on facilities, training, indications, and patient management. Heart Rhythm, 2009; 6: 1085-1104.

7. Goyal SK, Punnam SR, Verma G et al. Persistent left superior vena cava: A case report and review of literature. Cardiovasc Ultrasound, 2008; 10; 6: 50 .

8. Webb WR, Gamsu G, Speckman JM et al. Computed tomographic demonstration of mediastinal venous anomalies. Am J Roentgenol, 1982; 139: 157-161.

9. Cheng $Z$, Deng $\mathrm{H}$, Cheng $\mathrm{K}$ et al. Implantation of a pacemaker in a patient with persistent left superior vena cava and absence of right superior vena Cava. Int J Cardiol, 2013; 30: 168.

10. Korantzopoulos P, Grekas G, Goudevenos JA. Right-sided implantation of a cardiac resynchronization therapy defibrillator in a case of persistent left superior vena cava. Hellenic J Cardiol, 2013; 54: 224-226.

11. Vijayvergiya R, Shrivastava S, Kumar A et al. Transvenous defibrillator implantation in a patient with persistent left superior vena cava. World J Cardiol, 2013; 26: 109-110.

12. Paraskevaidis S, Konstantinou DM, Theofilogiannakos E et al. Persistent left superior vena cava: Report of 3 patients undergoing device implantation. Herz, 2014; 39: 163-165.

13. Seow SC, Agbayani MF, Lim TW et al. Left ventricular pacing in persistent left superior vena cava: a case series and potential application. Europace, 2013; 15: 845-848.

14. Guenther M, Kolschmann S, Rauwolf TP et al. Implantable cardioverter defibrillator lead implantation in patients with a persistent left superior vena cava-feasibility, chances, and limitations: Representative cases in adults. Europace, 2013; 15: 273-277.

15. Morani G, Bergamini C, Toniolo M et al. How many leads through persistent left superior vein cava and coronary sinus? J Electrocardiol, 2010; 43: 663-666.

16. Parikh MG, Halleran SM, Bharati S et al. Successful percutaneous cardiac resynchronization despite an occlusive Thebesian valve. Pediatr Cardiol, 2011; 32: 1223-1227.

17. Kortner A, Keyser A, Schmid C. Cardiac resynchronization therapy in patients with absent right but persistent left superior vena cava. Thorac Cardiovasc Surg, 2009; 57: 232-233.

18. Biffi M, Bertini M, Ziacchi M et al. Clinical implications of left superior vena cava persistence in candidates for pacemaker or cardioverterdefibrillator implantation. Heart Ves, 2009; 24: 142-146.

19. Lyon X, Kappenberger L. Implantation of a cardiac resynchronization system for idiopathic dilated cardiomyopathy in a patient with persistent left superior vena cava using an experimental lead for left ventricular stimulation. Pacing Clin Electrophysiol, 2000; 23 : 1439-1441.

20. Gasparini M, Mantica M, Galimberti P et al. Biventricular pacing via a persistent left superior vena cava: Report of four cases. Pacing Clin Electrophysiol, 2003; 26: 192-196.

21. Rivero-Ayerza M, van Belle Y, Mekel J et al. Left ventricular lead implantation assisted by magnetic navigation in a patient with a persistent left superior vena cava. Int J Cardiol, 2007; 116: e15-e17.

22. Palma EC, Eugenio PL. Implantation of a biventricular ICD system in a patient with a persistent left superior vena cava. Clin Cardiol, 2007; 30: 204.

23. Brooks R, Jackson G, McGovern BA et al. Transvenous cardioverter-defibrillator implantation via persistent left superior vena cava. Am Heart J, 1995; 129: 195-197.

24. Williams TA Jr, Abe O, Mitre CA et al. Low defibrillation threshold in a patient with a dual-coil defibrillator lead implanted through a persistent left superior vena cava. Pacing Clin Electrophysiol, 2012; 35: e274-e275. 